$04.1 ; 13.1$

\title{
Влияние потока низкотемпературной плазмы азота на морфологию, электрические и УФ-проводящие свойства пленок ZnO на сапфире
}

\author{
(c) М.Х. Гаджиев ${ }^{1}$, А.С. Тюфтяев ${ }^{1}$, А.Э. Муслимов $^{2}$, В.М. Каневский ${ }^{2}$, А.М. Исмаилов ${ }^{3}$, В.А. Бабаев ${ }^{3}$ \\ ${ }^{1}$ Объединенный институт высоких температур РАН, Москва, Россия \\ ${ }^{2}$ Институт кристаллографии им. А.В. Шубникова ФНИЦ „Кристаллография и фотоника“ РАН, Москва, Россия \\ ${ }^{3}$ Дагестанский государственный университет, Махачкала, Россия \\ E-mail: makhach@mail.ru
}

Поступило в Редакцию 27 июня 2019г.

В окончательной редакции 22 июля 2019 г.

Принято к публикации 22 июля 2019г.

\begin{abstract}
Приведены результаты исследования влияния потока высокоэнтальпийной низкотемпературной плазмы азота, генерируемого плазмотроном постоянного тока, на морфологию, электрические и УФ-проводящие свойства пленок $\mathrm{ZnO}$ на сапфире. Показано, что сопротивление пленок $\mathrm{ZnO}$ после обработки плазмой азота возрастает (максимально в $10^{4}$ раз) и они демонстрируют отчетливый отклик на ультрафиолетовое освещение. УФ-чувствительность по току и контрастность тока образцов при $6 \mathrm{~V}$ имеют величины порядка $3.6 \cdot 10^{-5} \mathrm{~A} / \mathrm{W}$ и 16 соответственно. Время нарастания и спада фототока $\sim 0.45 \mathrm{~s}$.
\end{abstract}

Ключевые слова: оксид цинка, низкотемпературная плазма, плазмотрон.

DOI: 10.21883/PJTF.2019.22.48639.17951

Оксид цинка $(\mathrm{ZnO})$ благодаря значительной запрещенной зоне $(3.3 \mathrm{eV}$ при $300 \mathrm{~K})$ и большой энергии связи экситонов $(60 \mathrm{MeV})[1,2]$ является весьма перспективным для создания самого широкого класса оптоэлектронных устройств. Одним из основных направлений является ультрафиолетовая (УФ) электроника, в частности изготовление фотодетекторных устройств на основе $\mathrm{ZnO}$. Беспримесные пленки $\mathrm{ZnO}$ обладают электронным типом проводимости ввиду высокой концентрации собственных дефектов доноров, таких как межузельный цинк, вакансии кислорода, и слабоконтролируемого легирования примесями типа атомов водорода [3]. В процессе УФ-освещения $\mathrm{ZnO}$ именно электроны образуют избыточный относительно равновесной концентрации заряд [4], определяющий чувствительность фотодетектора. Как следствие, повышение чувствительности фотодетекторов неизбежно связано с необходимостью снижения равновесной концентрации носителей заряда. Известно, что отжиг $\mathrm{ZnO}$ на воздухе приводит к увеличению сопротивления за счет снижения концентрации вакансий кислорода, однако такой подход не позволяет сократить время релаксации фототока, являющегося основной проблемой УФ-детекторов на основе $\mathrm{ZnO}$. Для ее устранения применяются структуры $\mathrm{ZnO}$ с аномально развитой поверхностью типа массива нитевидных нанокристаллов [5,6] ценой значительного усложнения технологии их получения. Возникает необходимость в поиске оптимального способа, коим может являться допирование пленок $\mathrm{ZnO}$ акцепторной примесью. При близких значениях ионного радиуса $\mathrm{N}^{+}$ и $\mathrm{O}^{+}$величина электроотрицательности у азота (3.0) меньше, чем у кислорода (3.5) [7]. По этой причине атомы азота внедряются в анионную подрешетку $\mathrm{ZnO}$ как примесь замещения, уменьшая концентрацию точечных вакансий $V_{\mathrm{O}}$ и проявляя себя в $\mathrm{ZnO}$ как акцепторная примесь. Следовательно, внедрение примеси азота приводит к увеличению сопротивления, а при достаточной концентрации, вероятно, приведет и к смене типа проводимости в $\mathrm{ZnO}$. Таким образом, повышению фоточувствительности и сокращению времени релаксации фототока может способствовать формирование высокой концентрации центров захвата и рекомбинации носителей заряда в тонких пленках $\mathrm{ZnO}: \mathrm{N}$ путем внедрения азота. Известно несколько способов получения пленок $\mathrm{ZnO}$, допированных азотом: магнетронное распыление в атмосфере азота [8]; постростовая обработка пленок в азотной плазме [9]. При этом авторами отмечается сложность получения и низкие эксплуатационные характеристики таких образцов: требуется длительное время обработки (до $20 \mathrm{~h}$ ); в процессе эксплуатации азот десорбируется и имеется тенденция к восстановлению высокой проводимости $n$-типа. Одной из причин является значительная энергия активации реакций, протекающих с участием азота. Для повышения химической активности азота необходимо проводить процесс при высоких температурах, которых можно достичь, например, при использовании плазмотрона. В настоящей работе впервые предложена методика допирования азотом пленок $\mathrm{ZnO}$ посредством их обработки в потоке низкотемпературной высокоэнтальпийной плазмы азота с использованием плазмотрона. Представлены результаты исследований влияния предложенного метода обработки на морфологию, электрические и УФ-проводящие свойства эпитаксиальных пленок (0001) $\mathrm{ZnO} n$-типа проводимости размером $1 \times 1 \mathrm{~cm}$ на подложке сапфира толщиной $\sim 450 \mathrm{~nm}$, полученных методом магнетрон- 
ного распыления на автоматизированном магнетронном комплексе „ВАТТ АМК-МИ“ [10].

В качестве источника низкотемпературной высокоэнтальпийной плазмы использовался плазмотрон с расширяющимся каналом выходного электрода [11], генерирующий на выходе слабо расходящуюся плазменную струю азота диаметром $D=8-10 \mathrm{~mm}$ с энтальпией до $50 \mathrm{~kJ} / \mathrm{g}$ и среднемассовой температурой $7-10 \mathrm{kK}$ при полной электрической мощности дугового разряда $20-50 \mathrm{~kW}$ и расходе плазмообразующего газа $1-3 \mathrm{~g} / \mathrm{s}$. Оценка параметров плазмы в зоне взаимодействия плазмы с образцом проводилась по данным анализа спектров, полученных с помощью трехканального оптоволоконного спектрометра AvaSpec 3648 со спектральным разрешением $0.2-0.5 \mathrm{~nm}$ в диапазоне $220-850 \mathrm{~nm}$ [12]. В зоне взаимодействия плазмы с образцом среднемассовая температура потока составляла $\sim 7 \mathrm{kK}$ при концентрации электронов $10^{15} \mathrm{~cm}^{-3}$.

Микроскопические, спектроскопические и электрические исследования проводились на атомно-силовом микроскопе „NtegraAura“ (изготовлен фирмой НТ-МДТ, Зеленоград) в полуконтактном режиме и на растровом электронном микроскопе JEOL. Тип носителей в пленках $\mathrm{ZnO}$ определялся путем измерения эффекта Холла при комнатной температуре в конфигурации Ван-дер-Пау.

Для исследуемых структур при комнатной температуре проводились измерения вольт-амперных характеристик, а также фототока в процессе фотовозбуждения и после его прекращения. Образцы возбуждались УФлампой с диапазоном длин волн $250-400 \mathrm{~nm}$ и поверхностной плотностью потока энергии $\sim 1.5 \mathrm{~W} / \mathrm{m}^{2}$. Предварительно на образцы с помощью термического испарения наносились пленочные алюминиевые контакты, дающие хороший омический контакт с оксидом цинка [13].

Электронно-микроскопические изображения поверхности пленки $\mathrm{ZnO}$ до (рис. 1, $a$ ) и после (рис. 1, $b$ ) обработки в потоке плазмы азота позволили обнаружить значительные различия как в морфологии, так и в шероховатости. Можно увидеть, что в процессе обработки поверхность пленки растравливается. По данным атомно-силовой микроскопии шероховатость после обработки увеличивается в 1.2 раза. По всей видимости, воздействие на образец потока плазмы азота приводит к модификации его приповерхностного слоя в виде уплотнения и рекристаллизации в результате разогрева до температур свыше $1000 \mathrm{~K}$. Также возможным механизмом уплотнения и сглаживания структуры пленки $\mathrm{ZnO}$ является заполнение атомами азота точечных вакансий $V_{\mathrm{O}}$. По данным рентгеновского микроанализа (рис. 1) концентрация примесных атомов азота увеличивается с 1.27 до $2.41 \%$. Рекордного уровня легирования эпитаксиальных пленок $\mathrm{ZnO}$ азотом с предельной концентрацией азота 7.5 at.\% [8] достигнуть в нашем эксперименте не удалось. По всей видимости, необходимо подбирать время обработки и температуру плазмы, однако можно наблюдать (рис. 2) резкое увеличение сопротивления (максимально в $10^{4}$ раз) и легкое нарушение симметрии вольт-амперной характеристики пленок после обработки. Изменения типа носителей, согласно измерениям с помощью метода Холла, в пленках не произошло.

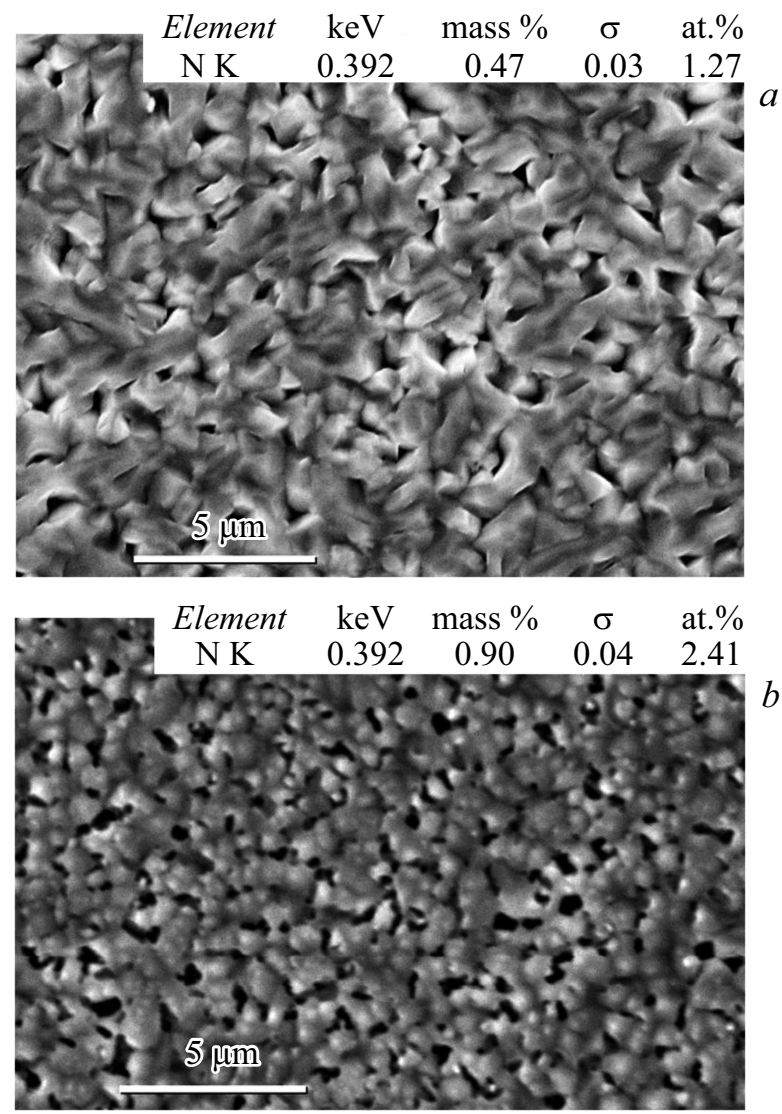

Рис. 1. Электронно-микроскопические изображения и данные рентгеновского элементного микроанализа пленки $\mathrm{ZnO}$ до обработки $(a)$ и после обработки в потоке низкотемпературной плазмы азота $(b)$.

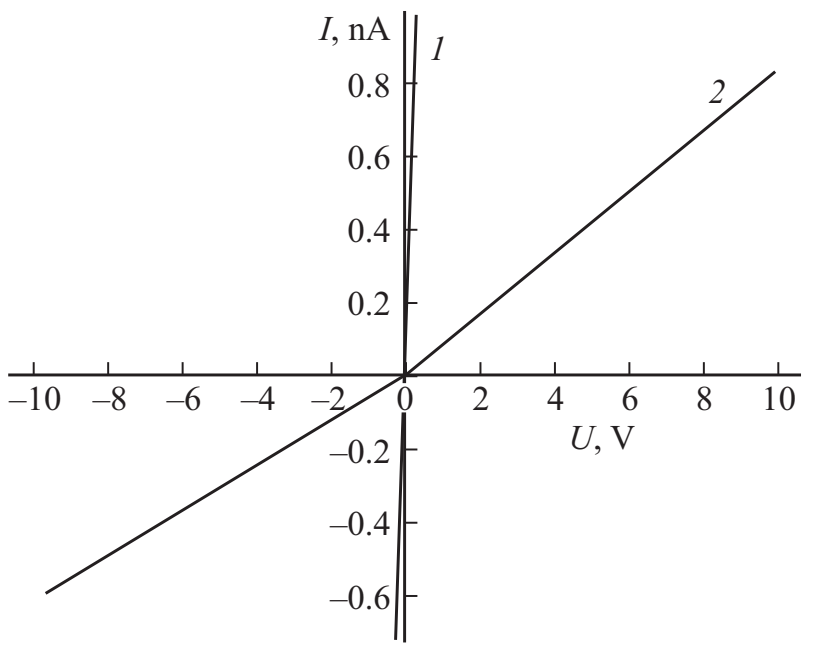

Рис. 2. Вольт-амперная характеристика образцов $\mathrm{ZnO}$ до (1) и после (2) обработки в плазме азота. 

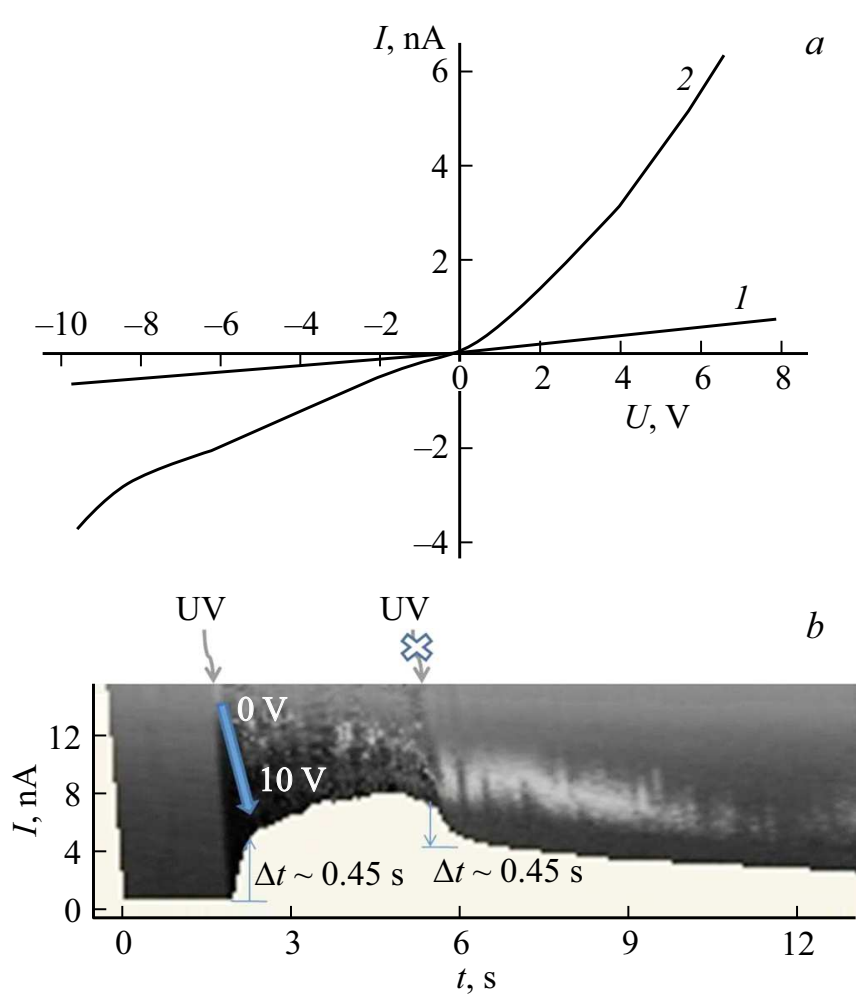

Рис. 3. $a-$ вольт-амперная характеристика (область положительного напряжения смещения) образца $\mathrm{ZnO}$, обработанного в плазме азота, до (1) и после (2) УФ-освещения. $b-$ трехмерное представление кинетики нарастания и спада фототока образца $\mathrm{ZnO}$, обработанного в плазме азота, в области положительного напряжения смещения $(0-10 \mathrm{~V})$. На схеме указаны моменты включения и выключения УФ-освещения.

Проверка резистивного отклика пленки $\mathrm{ZnO}$ на УФосвещение показала, что до обработки характерна низкая токовая УФ-чувствительность $\left(\sim 10^{-7} \mathrm{~A} / \mathrm{W}\right)$ и токовый контраст $(\sim 1-2 \%)$ при $10 \mathrm{~V}$. После обработки отклик был значительно отчетливее, чувствительность возросла до $3.6 \cdot 10^{-5} \mathrm{~A} / \mathrm{W}$ при $6 \mathrm{~V}$ (рис. 3). Следует заметить, что данная величина значительно меньше чувствительности фотодетекторов на основе $\mathrm{ZnO}$ с аномально развитой поверхностью $\left(\sim 10-10^{-2} \mathrm{~A} / \mathrm{W}\right)$. Однако обработанный образец демонстрировал высокий токовый контраст (максимальное значение отношения фототока к темновому току $I_{o n} / I_{\text {off }}$ при положительном смещении составляло 16), который незначительно зависел от приложенного напряжения. Основную роль в кинетике нарастания и спада фототока в образцах $\mathrm{ZnO}$ после плазменной обработки играют рекомбинация или захват на центрах акцепторного типа. Согласно [4], атомы кислорода, осажденные на поверхности, захватывают электроны из приповерхностных слоев $\mathrm{ZnO}$, образуя обедненную электронами зону, которая отвечает за низкую темновую проводимость. Наблюдаемые при этом фотостимулированные процессы можно интерпретировать следующим образом. Основная часть акцепторных центров после обработки в плазме азота фор- мируется в приповерхностной области. На них может нейтрализовываться (и впоследствии десорбироваться) отрицательно заряженный адсорбированный на поверхности кислород. УФ-освещение рождает дополнительно электронно-дырочные пары. Дырки ускоряют процесс десорбции с поверхности ионизованных атомов кислорода, освобождая места для осаждения нейтральных. При этом рожденные УФ-освещением электроны могут быть захвачены либо рекомбинировать на акцепторных центрах. И только часть из них участвует в фототоке. Токовая контрастность в таком случае может быть значительной, при этом общая фоточувствительность имеет сравнительно малую величину.

Нарастание и спад фототока носили идентичный характер (рис. $3, b)$ и состояли из короткой и длинной компонент. Короткие компоненты имели одинаковую длительность $\sim 0.45 \mathrm{~s}$ с постоянной времени $\sim 0.29 \mathrm{~s}$. Длинные компоненты различались: $\sim 3-4$ и $\sim 10-12 \mathrm{~s}$ для областей нарастания и спада соответственно. Скорость рекомбинации зависит от концентрации сгенерированных носителей. Поэтому на начальном этапе после включения УФ-освещения наблюдается резкий рост фототока, после чего происходит насыщение. Увеличение длинной компоненты при отключении УФ-освещения обусловлено низкой скоростью рекомбинации носителей, в основном протекающей через ловушки рекомбинации. По всей видимости, доля электронных ловушек с высоким барьером для захвата электронов значительна.

Воздействие высокоэнтальпийной низкотемпературной плазмы азота со среднемассовой температурой $7 \mathrm{kK}$ и концентрацией электронов $10^{15} \mathrm{~cm}^{-3}$ на пленки $\mathrm{ZnO}$ позволяет увеличивать их сопротивление (максимально в $10^{4}$ раз). После модифицирования пленки $\mathrm{ZnO}$ демонстрируют отчетливый отклик на ультрафиолетовое освещение. УФ-фоточувствительность по току и контрастность тока образцов при напряжении $6 \mathrm{~V}$ достигают величин $3.6 \cdot 10^{-5} \mathrm{~A} / \mathrm{W}$ и 16 соответственно. Нарастание и спад фототока носят идентичный характер и состоят из короткой и длинной компонент. Короткие компоненты нарастания и спада имеют одинаковую длительность $\sim 0.45 \mathrm{~s}$ и постоянную времени $\sim 0.29 \mathrm{~s}$. Длинные компоненты различаются: $\sim 3-4$ и $\sim 10-12$ s для областей нарастания и спада соответственно.

\section{Финансирование работы}

Работа выполнена при поддержке Министерства науки и высшего образования РФ в рамках работ по государственному заданию ФГБУ ОИВТ РАН в части нитридизации пленок и ФНИЦ „Кристаллография и фотоника“ в части характеризации пленок, а также при поддержке Российского фонда фундаментальных исследований (гранты 18-29-24203мк, 20-08-00598a).

\section{Конфликт интересов}

Авторы заявляют, что у них нет конфликта интересов. 


\section{Список литературы}

[1] Mishra Y.K., Adelung R. // Mater. Today. 2018. V. 21. P. 631651.

[2] Faraji N., Ulrich C., Wolff N., Kienle K., Adelung R., Kumar Y., Seidel J. // Adv. Electron. Mater. 2016. V. 2. P. 1600138.

[3] Desai M.A., Sartale S. // Cryst. Growth Design. 2015. V. 15. P. 4813-4820.

[4] Gimenez A.J., Yánez-Limón J.M., Seminario J.M. // J. Phys. Chem. C. 2011. V. 115. P. 282-287.

[5] Gupta A., Arunachalam Sh., Cloutier S., Izquierdo R. // ACS Photon. 2018. V. 5. P. 3923-3929.

[6] Postica V., Paulowicz I., Lupan O., Schütt F., Wolff N., Cojocaru A., Mishra K.Y., Kienle L., Adelung R. // Vacuum. 2018. V. 166. P. 393-398.

[7] Liu W.W., Yao B., Zhang Z.Z., Li Y.F., Li B.H., Shan C.H., Zhang J.Y., Chen D.Z., Fan X.W. // J. Appl. Phys. 2011. V. 109. P. 093518.

[8] Gorbatenko L.S., Novodvorsky O.A., Panchenko V.Ya., Khramova O.D., Cherebilo Ye.A., Lotin A.A., Wenzel C., Trumpaicka N., Bartha J.W. // Laser Phys. 2009. V. 19. P. $1152-1158$.

[9] Wang D., Zhao D., Wang F., Yao B., Shen D. // Phys. Status Solidi A. 2015. V. 212. P. 846-850.

[10] Власов В.П., Буташин А.В., Каневский В.М., Муслимов А.Э., Бабаев В.А., Исмаилов А.М., Рабаданов М.Х. // Кристаллография. 2014. Т. 59. № 3. С. 467-470.

[11] Исакаев Э.Х., Синкевич О.А., Тюфтяев А.С., Чиннов В.Ф. // ТВТ. 2010. Т. 48. № 1. С. 105-134.

[12] Гаджиев М.Х., Исакаев Э.Х., Тюбтяев А.С., Юсупов Д.И. // Письма в ЖТФ. 2016. Т. 42. В. 2. С. 44-49.

[13] Yang Z., Wang M., Song X., Yan G., Dingband Y., Baic J. // J. Mater. Chem. C. 2014. V. 2. P. 4312-4319. 